\title{
Identifying the Scale Thresholds for Field-Data Extrapolation via Spatial Analysis of Landscape Gradients
}

\author{
Chi-Ru Chang, ${ }^{1 *}$ Pei-Fen Lee, ${ }^{2}$ Mei-Ling Bai, ${ }^{3}$ and Tzer-Ton Lin $^{4}$
}

\begin{abstract}
${ }^{1}$ Department of Landscape Architecture, Chinese Culture University, 55 Hwa-kang Road, Yangmingshan, Shilin 111, Taipei, Taiwan; ${ }^{2}$ Institute of Ecology and Evolutionary Biology, National Taiwan University, 1 Roosevelt Road, Section 4, Taipei 106, Taiwan; ${ }^{3}$ Department of Zoology, National Taiwan University, 1 Roosevelt Road, Section 4, Taipei 106, Taiwan; ${ }^{4}$ Fushan Experimental Forest, Taiwan Forest Research Institute, P.O. Box 132, Ilan, Taiwan
\end{abstract}

\begin{abstract}
Despite recent advances in resolving the scale issue, it remains problematic that so many ecological field studies are still conducted only at small scales because of the constraints imposed by limited resources. To maximize the use of these data, it would be helpful if the researchers could provide guidelines for the appropriate range and scale for the extrapolation of the data and identify the new information that would be needed to extend the scope of their extrapolation. In this paper, we present a method that can be used to detect scale thresholds for the extrapolation of field data through spatial analyses of the physical landscape, using the Fushan Forest, Taiwan, as an example. First, the relationship between the vegetation and the physical landscape was inferred from sampleplot data; this information was in turn used to extrapolate the data over the whole forest area. We then compared the environmental variables in the sample plots versus those in the whole forest area
\end{abstract}

via principal component analysis, landscape classification, and spatial autocorrelation analysis. Analyses of the entire Fushan Forest area showed that there are at least three major spatial scales at which physical gradients are expressed: elevation at the scale of the full forest extent (more than 3,000 $\mathrm{m})$, topographic position at $550 \mathrm{~m}$, and aspect at $250 \mathrm{~m}$. Analyses of the sample plots showed that the plots captured only two of these gradients-topographic position and aspect, but not elevation. Therefore, information from the current field data can only be extrapolated to within $550 \mathrm{~m}$ from the sample plots; further information derived from cross-elevation samples is needed to extrapolate beyond that range.

Key words: landscape analysis; spatial autocorrelation; gradient analysis; subtropical rain forest; principal components analysis; landscape classification.

\section{INTRODUCTION}

In recent years, the issue of scale in ecology has been the subject of much discussion because, whereas important environmental concerns are manifested over large areas, most ecological studies are conducted in relatively small areas over short time periods. For example, questions pertaining to

Received 23 July 2004; accepted 16 December 2004; published online 15 March 2006.

*Corresponding author; e-mail: crchang@faculty.pccu.edu.tw habitat fragmentation, the conservation of biodiversity, and climate change require information and knowledge of ecological processes at local, landscape, regional, and global scales. However, most ecological studies are comparatively limited in space and time. Indeed, a survey of the ecological experiments published between 1980 and 1987 in the journal Ecology found that $50 \%$ of them were conducted on plots less than $1 \mathrm{~m}$ in diameter (Kareiva and Anderson 1986); and another such survey found that only $7 \%$ of the sampled 
ecological experiments had a time horizon of more than 5 years (Tilman 1989). As a result, ecologists often find it difficult to extrapolate the information and knowledge obtained at fine scales to infer consequences that may occur at broad scales.

Through decades of pioneering and scrutinizing, ecologists have become more sophisticated about the scale issue (see, for example, Ehleringer and Field 1993). Growth and maturation in this field has included the advancement of knowledge in the area of three fundamental sets of problems (Marceau 1999): (a) the detection of scale domains and thresholds, within which patterns do not change or change monotonically with changes in scale (Meentemeyer 1989; Wiens 1989); (b) the evaluation of the effects of scale change on the explanatory power of different variables (Wiens 1989); and (c) the determination of scaling laws, which addresses the transfer of information across spatial scales (Turner and others 1989).

Physiological-based models of biogeochemical responses to environmental change have progressed a long way from "big-leaf" models that assume the scaling from leaf to canopy to be linear (for example, Farquhar and others 1980; Farquhar and von Caemmerer 1982) to the understanding of scale-specific responses-for example, that the regulatory factors of transpiration change from stomatal mechanisms at the scale of individual leaf surfaces to climate at the scale of vegetation (Jarvis and McNaughton 1986) - and therefore to complex models that deal with specific problems in scaling, such as transient dynamics and feedbacks (for example, Betts and others 1997; Schimel and others 2000). Potential vegetation models have also evolved from the basic modeling of vegetation as a function of climate (for example, Holdridge 1947) to complicated models that account for competition, various combinations of plant functional types, and physiological and ecological constraints on vegetation distributions (for example, Woodward 1987; Prentice and others 1992; Reynolds and others 2001). Scale as an issue and potential solutions to the scale problem have also been addressed specifically in the literature (for example, Jarvis 1995; King 1991; Levin 1992; Rastetter and others 1992; Marceau and Hay 1999; Wu 1999), such that concepts and general guidelines that help to deal with the scale issue, such as hierarchy theory (O'Neill and others 1986) and the hierarchical patch dynamics paradigm (HPDP) [Wu and Loucks 1995; Wu and Levin 1997], are increasingly available. Also, more field surveys are now implemented at larger temporal and spatial scales, so that ecologists now have the evidence to show that it may not be valid to extrapolate trends obtained from a few local field studies to a larger spatial scale (for example, Böhning-Gaese and others 1994; Taper and others 1995).

Evidence that undercuts the validity of extrapolating results obtained from a few small-scale field studies to larger spatial scales, even as it confirms our doubts, is not particularly helpful when it comes to making individual decisions about the appropriate use of field data. Unlike ecological studies based on remotely sensed data, which provide complete data across the scope of interest and whose major problems center on the sensitivity of analytical results to the definition of data collection units (Marceau and Hay 1999), such as the modifiable areal unit problem (MAUP) (for example, Hay and others 2001) and the ambiguity in object identification among data sets of different resolutions (for example, Hall and others 2004), ecological studies based on field data suffer more from the problem of filling a map when the available data pertain to only a small percent of the area of interest. Although it is now understood that crossscale measurements or surveys must be made to adequately address the scale issue, current ecological field surveys and experiments that are still conducted only at small temporal and spatial scales, and thus are far inferior to their remote-sensingbased counterparts, are usually not the result of deliberate choice, but a difficult and sad compromise given the paucity of available resources. As a result, despite the awareness of scale domains as a concept, managers and other users of ecological information are often unsure about what can and cannot be implied from field data, and at what scales. It would be more constructive and useful if, in addition to general guidelines that serve more or less as cautioning, field researchers could provide specific and clear rules for the extrapolation of their data, equivalent to those available for remotelysensed data (for example, Marceau and Hay 1999).

Spatial autocorrelation analysis is one method commonly used in solving the scale problem. Spatial autocorrelation occurs when the same variable measured at two different locations of distance $d$ apart are positively or negatively correlated. Techniques such as spatial autocorrelation (for example, Ripley 1981) and autocovariation (for example, Rossi and others 1992; Legendre 1993) are used to analyze spatially explicit data collected at various specific locations across the landscape, so that their scale domains (also termed "characteristic scales") and their separating thresholds can be identified. Once the scale domains and thresholds have been identified, researchers are able to infer 
and propose hypotheses on causal relationships and then perform scientific experiments to establish causality. In hydrology, for example, variograms are often used to detect the dominant spatial hydrological processes affecting soil moisture (Entin and others 2000; Mohanty and others 2000; Western and others 2002, 2004). In ecology, variograms have also been used successfully to determine the dominant scale of variability in environmental variables (Meisel and Turner 1998) and to identify the scale domains of various physical variables that drive water balance, resulting in a hierarchical framework for the drivers of water balance in montane landscapes (Urban and others 2000). Once the scale domains of different variables are detected, the concurrence in scales of variability of different ecological factors, such as plants and soil nutrients (Greig-Smith 1979) or seabirds and their prey (Schneider and Piatt 1986), can then be used to facilitate the search for underlying patterns and mechanisms.

Landscape classification is another technique in which classification techniques are applied to divide the landscape into several classes of relatively homogeneous units. The division of a landscape can then be used as a basis for stratified sampling. In this way, the samples will better reflect the variability within a site, and locations with unique characteristics are less likely to be missed in the sampling process (Barnes and others 1982; Cherrill and Lane 1995; Bunce and others 1996). The partition of landscape units can also be used in applied ecology as a basis for spatial prediction models (Cherrill and others 1995; Mladenoff and others 1995) and for monitoring and management programs (Wright and others 1994; Merrill and others 1995). This technique has also been used as an analytical tool to assess the appropriateness of geographical frameworks such as ecoregions (Wright and others 1998).

The objective of this paper was to demonstrate the use of spatial analyses-in this case, spatial autocorrelation analysis and landscape classification-as a means for detecting the scale threshold within which it would be appropriate to extrapolate field data obtained from several small sample plots to larger spatial scales and for identifying the type of new information needed to extend that threshold. In a companion paper (Chang and others 2004), vegetation data from field study plots in the Fushan Experimental Forest, Taiwan, were used to predict the vegetation across the full extent of the forest. Because remotely sensed data did not provide sufficient information to separate the Fushan Forest landscape into convincing segments, we did this prediction by first inferring the relationship between vegetation and their environments with classification methods and gradient analyses, then using these relationships and geographic information systems, extrapolated the information obtained from the samples over the full extent of the forest.

This paper originated from our attempts to devise a method to examine whether such an extrapolation was valid. In this paper, the vegetation plots and the entire forest area were examined separately for major environmental gradients at different scales using spatial analysis. We believe that the scales at which the vegetation plots accurately capture the spatial structure of the intended area of extrapolation can be used to determine the threshold that defines the scale domain of valid extrapolation, whereas the scales and variables in which the vegetation plots fail to do so suggests the scale and location of the new samples and the types of new variables that would be needed to extend this scale threshold.

\section{Methods}

\section{Study Area}

Fushan Experimental Forest (Figure 1) is an International Long-Term Ecological Research (ILTER) site located $40 \mathrm{~km}$ southeast of Taipei in northeastern Taiwan $\left(\mathrm{N} 24^{\circ} 46^{\prime}, \mathrm{E} 121^{\circ} 43^{\prime}\right)$. The forest is approximately $6 \mathrm{~km}$ long and $4 \mathrm{~km}$ across, and it covers 1,097.9 ha of mountainous terrain. It is dissected from north to south by a branch of the Snow Mountain Range. To the east and west of this ridge are two rivers: Tsu-Keng Creek to the southeast and Ha-Pen Creek to the west (Chang and others 1986).

The climate is warm and moist, with an annual average temperature of $18.3^{\circ} \mathrm{C}$. Mean annual precipitation is $4,067 \mathrm{~mm}$, and average humidity is $96 \%$. Typhoons are frequent during the summer, with maximum wind gusts over $35 \mathrm{~m} / \mathrm{s}^{-1}$ (Mabery and others 1998).

The soil is strongly acidic ( $\mathrm{pH} 3.8-5.0)$, with a moderate quantity of organic matter in the sublayer $(2-5 \%)$. Yellow soil is found on ridges and stable slopes, colluvial soil is found on midhills and foothills, and Lithosols are found on very steep slopes or in streambeds (Lin and others 1996).

Previous studies of the vegetation in the area have classified it as a subtropical rain forest, transitioning to warm temperate rain forests $1,000 \mathrm{~m}$ above sea level. Dominant tree species are mostly broadleaf, belonging to the families Fagaceae, Lauraceae, Theaceae, Ebenaceae, and Juglandaceae. Chinkapin (Castanopsis carlesii) is the most dominant species. 


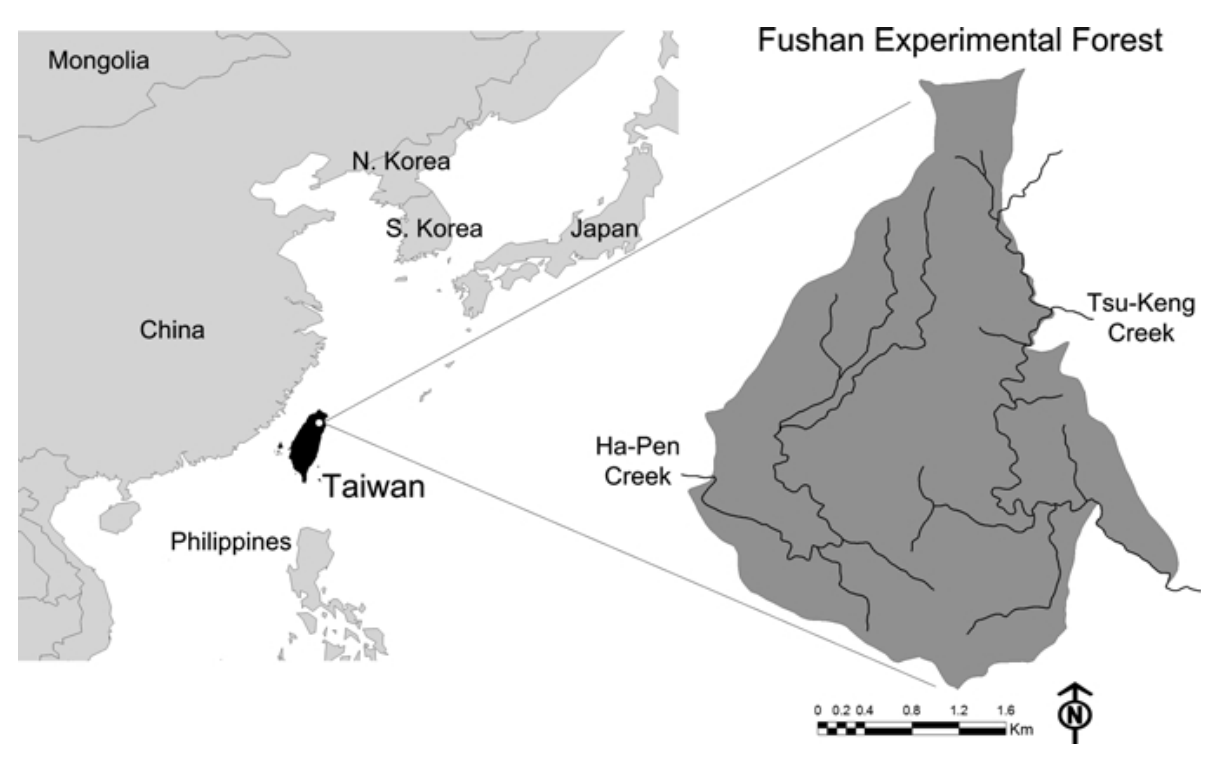

Figure 1. Location of Fushan Experimental Forest and the island of Taiwan. The two rivers in the area are Tsu-Keng Creek flowing towards the southeast, and Ha-Pen Creek flowing towards the west.

Table 1. List of Environmental Variables Used in the Analysis

\begin{tabular}{lll}
\hline Abbreviation & \multicolumn{1}{c}{ Definition } & \multicolumn{1}{c}{ Units } \\
\hline ELEV & Elevation & $\mathrm{m}$ \\
MDR & Mean Annual Direct Radiation & $\mathrm{cal} \mathrm{cm}^{-2} \mathrm{~d}^{-1}$ \\
MTR & Mean Annual Total Radiation & $\mathrm{cal} \mathrm{cm}^{-2} \mathrm{~d}^{-1}$ \\
RVD & Distance to River & $\mathrm{m}$ \\
SDDR & Standard Deviation in Annual Direct Radiation & \\
SDTR & Standard Deviation in Annual Total Radiation & degree $\left(^{\circ}\right)$ \\
SLP & Slope & \\
SOC & Soil Group-Colluvial Soil & \\
SOL & Soil Group-Lithosol & \\
SOY & Soil Group-Yellow Soil & \\
SPHA & Soil Parent Material-Shale & \\
SPLA & Soil Parent Material-Slate & $0-180$ \\
STH & Southness & $\mathrm{mE}$ \\
TMX & Location in the East-West Direction & $\mathrm{mN}$ \\
TMY & Location In The North-South Direction & -1 to 1 \\
TOPO & Topographic Position & $0-180$ \\
WEST & Westness & $\%$ \\
WLS & Whole Light Sky Space & \\
\hline
\end{tabular}

Other common tree species include Machilus thunbergii, Engelhardia roxburghiana, Litsea acuminata, and Machilus zuihoensis. The understory is composed of dense shrubs such as Blastus cochinchinensis and tree ferns such as Cyathea podophylla. The ground layer is covered with ferns, and Diplazium dilatatum is the most dominant species (Chang 1998; Kuo 1994; Lin and others 1996; Lin 1997).

\section{Environmental Data}

A total of 18 spatially explicit environmental variables (Table 1) were used in this study. These variables were derived from existing 1:5,000 maps of terrain, streams, and soil interpolated onto $12.5 \times 12.5 \mathrm{~m}$ grid maps. The $12.5 \times 12.5 \mathrm{~m}$ grid size was chosen earlier to fit the SPOT earth observation satellites images obtained from Taiwan's SPOT distributor. The spatial location of each grid cell was recorded using the transverse Mercator projection coordinate system ( $\mathrm{mE}$ and $\mathrm{mN})$. When analyzing the entire Fushan Forest landscape (the intended area of extrapolation), we used environmental variables from all of the grid cells within the Fushan Forest boundary. For 
analysis of the vegetation sample plots, environmental variables from only the grid cells that corresponded to the sample plots were used.

Topographic information, including slope $\left({ }^{\circ}\right)$, aspect $\left({ }^{\circ}\right)$, and topographic location, were derived from a digital terrain model (DTM) based on a 1:5,000 isoclines map of the area and using Arc/Info [Environmental Systems Research Institute, Redlands, CA, USA (ESRI 1997)]. Because aspect is a circular variable, it was transformed into two derived variables, southness and westness, where:

$$
\text { Southness }=180-\mid \text { aspect }-180 \mid
$$

such that south would be 180 and north 0 , and:

$$
\text { Westness }=|180-| \text { aspect }-270||
$$

such that west would be 180 and east 0. Topographic location is expressed as an index:

\section{Distance from valley - Distance from ridge Distance from valley + Distance from ridge}

This index has values between -1 and +1 , with higher values indicating upper slope areas closer to ridges $(+1)$, and lower values indicating areas closer to valleys $(-1)$.

Whole light sky space is defined as the proportion of sky space not obstructed by surrounding terrain (Hsia and Wang 1985). We used 16 viewing aspects, and the points with the largest blocked angle along each viewing aspect were used to define a polygon representing the sky space area not obstructed by surrounding terrain. The remaining solar radiation variables (in cal $\mathrm{cm}^{-2} \mathrm{~d}^{-1}$ ) were calculated with SolarImg (Harmon and Marks 1995), a program developed for the H.J. Andrews Experimental Forest in Oregon, USA. This program estimates solar radiation input to a site based on the site's latitude, elevation, aspect, slope, and cloud cover, following the methods of Bonan (1989) and Nikolov and Zeller (1992).

Streams data was digitized using a 1:5,000 streams map of the area. Distance to streams $(\mathrm{m})$ is defined as the minimum Euclidean distance of a site to streams.

Soil survey maps from a previous study (Lin and others 1996) were used to create digital maps containing information on soil types as suggested by the authors (yellow soil, colluvial soils, and Lithosols), parent material (shale or slate), and soil taxonomic order (Ultisol, Inceptisol, and Entisol).

\section{Vegetation Data and Vegetation Analysis}

In an earlier study (Lin and others 1995), the trees of the Fushan Experimental Forest were surveyed. Because photographs taken from the air did not provide sufficient disparity for the stratification of the landscape, field ecologists set out into the forest on foot, located relatively homogeneous areas within the forest based on site observations, and laid a $50 \times 10 \mathrm{~m}$ sample plot in the proximity of the center of each of these relatively homogeneous patches. The centers of the resulting 53 sample plots were then defined and mapped. Within each plot, all trees taller than $1.3 \mathrm{~m}$ were counted and identified; their diameter at breast height (dbh) was then measured and the basal area was calculated.

Because the exact direction and location of the $50 \times 10 \mathrm{~m}$ plots can no longer be identified, we evaluated the potential error for two alternatives: (a) using the grid cell corresponding to the mapped center of the plots, and (b) using the minimum area that will cover all possible plot coverage. The first alternative resulted in a $12.5 \times 12.5 \mathrm{~m}$ grid cell, omitting approximately $75 \%$ of the original plot (error of omission). The second alternative resulted in a $62.5 \times 62.5 \mathrm{~m}$ area, including $87.2 \%$ outside the original plot (error of inclusion). We therefore chose to use the first method, in which the environmental variables for the vegetation sample plots were retrieved from the grid cells corresponding to their mapped center.

Two types of information are generally inferred from vegetation data: whether the locations of tree species reflect certain environmental gradients in the landscape (that is, the variation in environmental factors across the landscape), thereby suggesting the major environmental gradients that determine tree species distribution; and if the tree species form distinct groups or classes, and how these classes distribute across the landscape. To determine if the locations of tree species reflect environmental gradients, detrended correspondence analysis (DCA), [Hill and Gauch 1980] was used to detect the gradient in tree species composition, using the PC-ORD program [MjM Software Design, Gleneden Beach, OR, USA (McCune and Mefford 1999)]; and the relationship between vegetation gradients and environmental variables was determined through stepwise regression, using S-plus 6 for Windows (Insightful 2001, Seattle, WA, USA). To determine if the vegetation formed classes, the species were clustered into different types with two-way indicator species analysis (TWINSPAN), also using PC-ORD, and the relationship between vegetation classes and environ- 
mental variables was determined through discriminant analysis using SAS software [SAS Institute, Cary, NC, USA (SAS 1994)]. To minimize the influence of local species, species that were present in less than $5 \%$ of the sample sites were removed from the vegetation analysis. The vegetation data from the sample plots were then extrapolated across the Fushan Forest landscape using these relationships, the environmental data maps, and Arc/Info, producing maps that predicted vegetation classes and vegetation gradients (Chang and others 2004).

\section{Analysis of Environmental Gradients}

Environmental data from all grid cells within the Fushan Forest were analyzed for their major environmental gradients in the whole study area with principal components analysis (PCA) using the correlation matrix and PC-ORD, such that the dimensions with the most variation within the $n$ dimensional environmental factor space could be detected. A similar analysis was performed on the environmental variables of the sample plots, and the results were compared with those from the whole forest area.

\section{Landscape Classification}

Using the major PCA axes, which accumulate $90 \%$ variance as input variables, classification of the Fushan Forest landscape was done using cluster analysis with the average linkage algorithm and the SAS statistical package (SAS Institute 1994).

\section{Spatial Autocorrelation Analysis of the Physical Landscape}

Spatial autocorrelation was used to detect and compare the spatial structure of the environmental variables of the vegetation sample plots versus those of the whole Fushan Forest area. Of the many methods available for the analysis of spatial structure, semivariance was our preferred initial choice because the ranges (distance at which the saturation of variance occurs) from resulting semivariograms can be used to infer the characteristic patch sizes in the various environmental gradients.

Semivariance is estimated by:

$$
\gamma(d)=\frac{1}{2 n_{d}} \sum_{i}^{n_{d}}\left(z_{i+d}-z_{i}\right)^{2}
$$

where $\gamma(d)$ is the semivariance at lag distance class $d, n_{d}$ is the number of sample pairs in lag class $d, z_{i}$ is the variable measured at location $i$ and $z_{i+d}$ is the variable measured at location $i+d$, which in turn is a location at lag class $d$ from location $i$.

The semivariograms from the vegetation sample plots, however, were undecipherable, because a sample size of 53 plots was too small and yielded substantial noise, so that a sill and corresponding range cannot be satisfactorily detected. As a result, spatial autocorrelation (a mirror image of the semivariogram) with Moran's I (Sokal and Oden 1978) was used, because this index can be permutated for expected values and variances, and a significance test can be performed for small sample sizes.

Moran's I is calculated as:

$$
I(d)=n \sum_{i j} w_{i j}\left(z_{i}-\bar{z}\right)\left(z_{j}-\bar{z}\right) / W \sum_{i=1}^{n}\left(z_{i}-\bar{z}\right)^{2}
$$

where $I(d)$ is the Moran's I at lag distance class $d, n$ is number of samples, $w_{i j}$ is the weight given to the sample pair $i-j$ such that only pairs with a distance of lag class $d$ will be included in the summation, $z_{i}$ and $z_{j}$ is the variable measured at location $i$ and $j$, and $W$ is the sum of the matrix of weights excluding the diagonals. Moran's I values range from -1 to +1 , with +1 indicating perfect positive autocorrelation and -1 indicating perfect negative autocorrelation at lag distance class $d$. A Moran's I value of 0 indicates that data pairs at lag class $d$ apart are not correlated to each other. The expected values and variances were calculated with 1,000 permutations under assumption of sampling without replacement, using the methods of Sokal and Oden (1978).

\section{RESUltS}

\section{Vegetation Analysis}

Here we provide a generalized, short description of the relationship between the vegetation and the environmental variables established via the vegetation analysis, so that the reader will be able to follow the discussion. More detailed information on both the vegetation analysis and vegetation extrapolation models can be found in Chang and others (2004).

Vegetation classification using TWINSPAN results in a dendrogram (Figure 2) in which the sample plots are separated into two groups at a time according to their similarity and dissimilarity in vegetation. The first-level division (Division I) separated the valley sites from the upland sites. In the second-level division, the upland sites were 


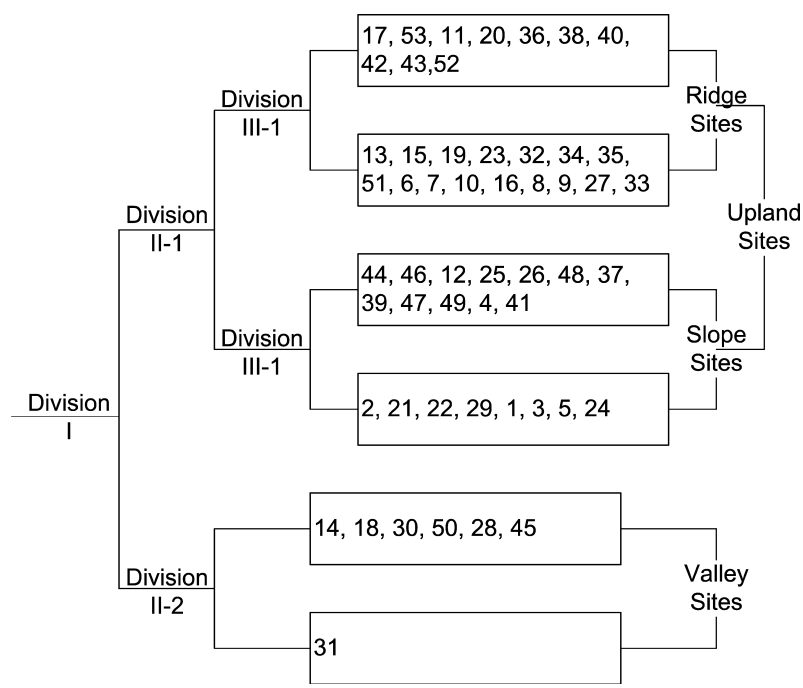

Figure 2. Dendrogram from TWINSPAN results. The numbers shown in the boxes are site numbers. Indicator species for division I are Machilus kusanoi $1(+)$ and Oreocnide pedunculata 2(+); for division II-1, Myrsine sequinii 1(-) and Elaeocarpus japonicus 5(-), for division II-2, Callicarpa formosana $1(+)$.

divided into ridge sites and mid-slope sites (Division II-1), but in the valley group, one site (site 31) was singled out based on the presence of Callicarpa formosana (Division II-2), a division we determined to be ineffectual and thus defined the valley group terminal. The third-level divisions in the upland sector (Divisions III-1, 2) further separated the ridge and slope groups into subgroups that cannot be clearly identified. We therefore chose to define the vegetation into three groups that can be explained by topography: ridge sites, slope sites, and valley sites.

Of the three vegetation types (Table 2), the valley community is the most distinct and is characterized by the dominance of mesic species (for example, Machilus kusanoi), the relative abundance of gap species (for example, Lagerstroemia subcostata), and the absence of xeric species (for example, Meliosma squamulata). The ridge and mid-slope communities are quite similar in their species composition, but the ridge community differs from the slope community by the presence of some xeric species (for example, Myrsine sequinii) and the absence of some mesic species (for example, Oreocnide pedunculata) and gap species (for example, Lagerstroemia subcostata).

The DCA results also separate the samples and species using species affiliation. The first DCA axis, which identifies the samples in which the vegetation are most dissimilar, separated the samples (Figure 3) and species (not shown) occurring on ridges from those in valleys, whereas axis 2 separated part of the slope sites from the rest. When plot DCA scores were compared to their environmental variables (Table 3), the first DCA axis was strongly related to topographic position and soil types, the second axis was most related to elevation and factors related to total annual solar radiation input, such as whole light sky space and mean annual direct and mean annual total solar radiation, and the third axis was most related with southness, slope, and the variance in total annual solar radiation.

\section{Characteristics of Environmental Variables in the Vegetation Plots versus Those of the Whole Fushan Forest Area}

Although the vegetation sample plots have an average elevation $(774 \mathrm{~m})$ similar to that of the all the grid cells in the Fushan Forest $(770 \mathrm{~m})$, they span only $36.6 \%$ of Fushan's full range (Table 4). The average slope of the vegetation plots is approximately $10^{\circ}$ less than the average of the whole study area, and the average whole light sky space is approximately $10 \%$ more than the average for the whole study area. The vegetation plots had average direct and total solar radiation values similar to those of the whole study area at 237.9 and $421.9\left(\mathrm{cal} / \mathrm{cm}^{-2} \mathrm{~d}^{-1}\right)$ respectively, but they also covered a smaller range.

\section{Principal Components Analysis}

A PCA of the environmental variables from all the grid cells of the Fushan Forest showed that $95 \%$ of the variance can be captured by the first five axes (Table 5). The first PCA axis is most associated with elevation, mean direct radiation, and mean total radiation; the second is most associated with southness and the variance in total radiation; the third is most associated with whole light sky space and slope; and the fourth and fifth axes are both associated with westness and slope.

A PCA of the environmental variables from the vegetation plots showed that only $65 \%$ of the variance can be captured by the first five axes, indicating that variance in the sample plots is spread into more dimensions than in the whole forest. The first PCA axis is most associated with variables related to the topographic location of the site, such as elevation, topographic position, distance to streams, the various representations of solar radiation, and the highly topography-related Lithosol. The second, third, and sixth PCA axes are most associated with soil types. The second axis is associated with soils originating from slate; the third axis is associated 
Table 2. Analysis of Vegetation in Different TWINSPAN Community Types

\begin{tabular}{|c|c|c|c|c|}
\hline & All Sites & Ridge-type & Mid-slope & Valley-type \\
\hline Total No. of Species & $92(100 \%)$ & $75(81.5 \%)$ & $64(69.6 \%)$ & $42(45.7 \%)$ \\
\hline Average No. of Species/Plot & $26(28.3 \%)$ & $31.5(34.2 \%)$ & $22(23.9 \%)$ & $18(19.6 \%)$ \\
\hline No. of Species Shared & $28(30.4 \%)$ & & & \\
\hline With Mid-slopes & - & $53(57.6 \%)$ & - & - \\
\hline With Valley-types & - & $28(30.4 \%)$ & $36(39.1 \%)$ & - \\
\hline No. of Unique Species ${ }^{a}$ & - & $22(23.9 \%)$ & $3^{\mathrm{b}}(3.3 \%)$ & $6(6.5 \%)$ \\
\hline No. of Uniquely Absent Species ${ }^{c}$ & - & $8(8.7 \%)$ & 0 & $25(27.2 \%)$ \\
\hline \multicolumn{5}{|l|}{ Most Dominant Species ${ }^{\mathrm{d}}$} \\
\hline 1 & Castanopsis carlesii & Castanopsis carlesii & Castanopsis carlesii & Machilus kusanoi \\
\hline 2 & Machilus thunbergii & Machilus thunbergii & Machilus thunbergii & Phoebe formosana \\
\hline 3 & Litsea acuminata & Meliosma squamulata & Litsea acuminata & Machilus zuihoensis \\
\hline \multicolumn{5}{|c|}{$\begin{array}{l}{ }^{a} \text { Number of species found only in the specific community type. } \\
{ }^{b} \text { All species unique to the mid-slope community type occurred in only one site. } \\
{ }^{c} \text { Number of species that are absent only in the specific community type. } \\
{ }^{d} \text { Species are listed in order of dominance. }\end{array}$} \\
\hline
\end{tabular}

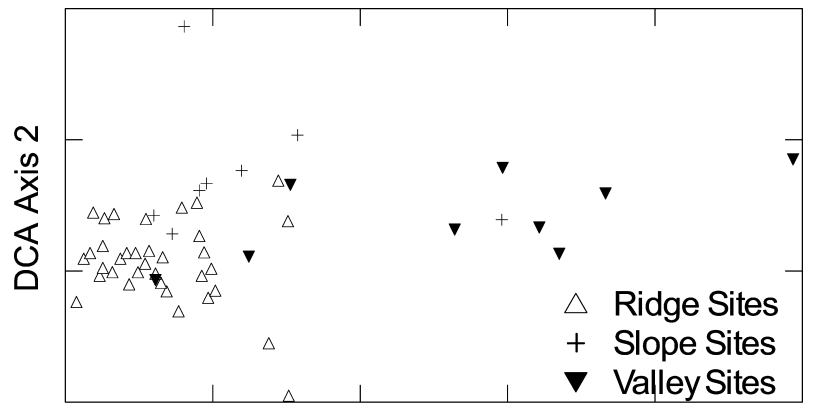

DCA Axis 1

Figure 3. Vegetation plots graphed in DCA axis 1 and axis 2 space, displayed by their topographic position index (TPI). Sites with TPI values between -1 and -0.34 are marked as valley sites; sites with values between -0.33 and 0.33 are marked as mid-slope sites; and sites with values between 0.34 and 1 are marked as ridge sites.

with soils originating from shale; and the sixth axis is associated with yellow soils. The fourth and fifth axes are most associated with aspect, with the fourth axis associated with southness and the variance in annual total solar radiation and the fifth axis associated with westness.

\section{Landscape Classification}

The first split from the landscape classification results separates the northern part and the southern tip of the forest, where the elevation is higher than the rest of the landscape (1-1, Figures 4,5) from the remainder of the forest (1-2). The second split separates the medium- to lower-elevation types (1-2) into valleys (2-2) and uplands (2-1). The third, fourth, and fifth splits separate the above three classes each into two types: The high-elevation group (1-1) is further separated by elevation, with the highest-elevation areas closest to Mount Ah-yu (3-1, Highest) being separated from the rest (3-2, High); the valley group (2-2) is further separated by aspect, with one group consisting of predominantly north-facing slopes (4-1, North-facing Valley) and the other consisting of predominantly south-facing slopes (4-2, South-facing Valley); and the mid-elevation upland group (2-1) is also separated by aspect, with one group consisting of predominantly north-facing slopes (5-1, North-facing Upland) and the other consisting of predominantly south-facing slopes (5-2, South-facing Upland).

Analysis of the distribution of the vegetation plots among the landscape classes (Figure 5B) showed that the vegetation plots were mostly distributed in the mid-elevational uplands of the landscape $(50.9 \%$ north-facing and $26.4 \%$ southfacing), with some distributed in the north-facing valley types $(13.2 \%)$, a few in the high sites $(5.7 \%)$ and in the south-facing valley types $(3.8 \%)$, and none in the highest sites $(0 \%)$.

\section{Spatial Structure of the Physical Environment}

The environmental variables from the whole Fushan Forest landscape are spatially autocorrelated at different scales (selectively shown in Figure 6). Elevation (Figure 6A) shows a decrease in autocorrelation as distance increases, indicating a gradient in elevation across the landscape. Topographic position (Figure 6B), distance to river, slope, westness, and whole light sky space show positive autocorrelation at closer ranges, with decreasing spatial autocorre- 
Table 3. Results from the Gradient Analysis

\begin{tabular}{lrrr}
\hline & \multicolumn{2}{c}{ DCA } \\
\cline { 2 - 4 } & Axis 1 & Axis 2 & Axis 3 \\
\hline Eigenvalue & 0.702 & 0.247 & 0.181 \\
Correlations with Selected Variables ${ }^{\mathrm{a}}$ & & & \\
$\quad$ Elevation & $-\mathbf{0 . 5 9 1}$ & -0.435 & -0.011 \\
Slope & -0.230 & 0.269 & -0.047 \\
Distance to River & -0.483 & -0.240 & 0.040 \\
Topographic Position & $-\mathbf{0 . 7 6 8}$ & -0.402 & 0.273 \\
Southness & -0.021 & -0.240 & 0.186 \\
Westness & 0.158 & 0.007 & -0.163 \\
Yellow Soil & -0.233 & -0.074 & -0.126 \\
Colluvial Soil & $-\mathbf{0 . 5 6 6}$ & -0.233 & 0.098 \\
Lithosols & $\mathbf{0 . 6 2 3}$ & 0.264 & 0.041 \\
Total Solar Radiation & $-\mathbf{0 . 5 8 0}$ & -0.440 & -0.215 \\
Variance in Total Solar Radiation & -0.256 & -0.089 &
\end{tabular}

$D C A$, detrended correspondence analysis.

${ }^{a}$ Correlations are DCA:Pearson correlations. Correlation values greater than 0.5 are highlighted in boldface.

Table 4. Comparison between Environmental Variables in the Vegetation Plots and the Fushan Forest Landscape

\begin{tabular}{lcc}
\hline Variable & Fushan Forest & Vegetation Plots \\
\hline Elevation $(\mathrm{m})$ & $770(386-1,451)$ & $774(611-1,001)$ \\
Slope $\left(^{\circ}\right)$ & $28.8(0.01-68.9)$ & $18.5(0.7-45.4)$ \\
Topographic Position & $0.21(-1.0-+1.0)$ & $0.43(-1.0-+1.0)$ \\
Distance from Rivers $(\mathrm{m})$ & $183.6(0-873.0)$ & $217.9(0-556.3)$ \\
Whole Light Sky Space $(\%)$ & $69.2(24.3-100)$ & $78.8(49.6-98.5)$ \\
Direct Solar Radiation $\left(\mathrm{cal} \mathrm{cm}^{-2} \mathrm{~d}^{-1}\right)$ & $237.7(214.2-279.2)$ & $237.9(227.8-251.8)$ \\
Total Solar Radiation $\left(\mathrm{cal} \mathrm{cm}^{-2} \mathrm{~d}^{-1}\right)$ & $421.7(403.7-452.0)$ & $421.9(414.2-432.2)$ \\
& & \\
\hline The values shown are averages; the ranges are given in brackets. & & \\
\hline
\end{tabular}

lation until 1,200 $\mathrm{m}$ for slope, $550 \mathrm{~m}$ for topographic position, distance to river, and whole light sky space, and $450 \mathrm{~m}$ for westness. Southness (Figure 6C), mean direct radiation, and mean total radiation also showed a pattern of having a gradient across the landscape, but with sites within $250 \mathrm{~m}$ having positive autocorrelation in southness. The standard deviation (SD) in total radiation (Figure 6D) and SD in direct radiation showed a gradient response until approximately 2,000 m, with sites within $250 \mathrm{~m}$ having positive autocorrelation in the SD in total radiation. The soil variables are positively autocorrelated at closer ranges but also decrease in autocorrelation with distances beyond 1,500-2,000 m.

Because of the small sample size, the autocorrelation patterns in the vegetation plots (also selectively shown in Figure 7 to correspond to Figure 6) were less clean, with significant excursions outside of the $95 \%$ confidence intervals beyond $750 \mathrm{~m}$. Despite such "noisiness" in the autocorrelation pattern, the vegetation plots still captured the major patterns in spatial structure of the whole study area. For example, the spatial autocorrelation structure for topographic position in the vegetation plots (Figure 7B) showed positive spatial autocorrelation at close distances until negative autocorrelation appears at $550 \mathrm{~m}$. Southness (Figure 7C) and the SD in total radiation (Figure 7D) also showed positive spatial autocorrelation at distances within approximately $250 \mathrm{~m}$. Elevation (Figure 7A), when compared to other variables, seemed to become "noisy" at a smaller scale, or to show a higher spatial autocorrelation at $450 \mathrm{~m}$ than at $250 \mathrm{~m}$, a pattern different from the whole study area. 


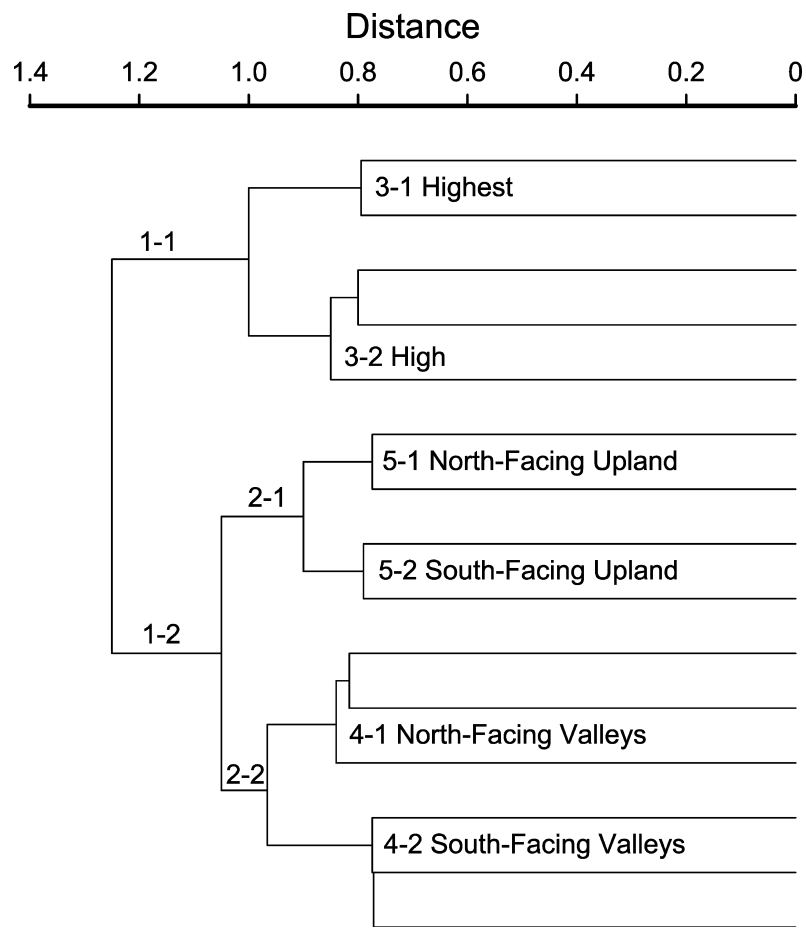

Figure 4. Classification tree of the Fushan Forest landscape. The tree is pruned slightly below where we determined that the classes were explainable. The first split separates the high elevation sites (1-1) from the mid- to lower-elevation sites (1-2). The second split separates the mid- to lower-elevation sites into upland sites $(2-1)$ and valley sites $(2-2)$. The third split separates the high-elevation sites into the highest areas to the north (3-1) and remaining high sites (3-2). The fourth and fifth splits separate the upland and valley groups each into predominantly north-facing slopes and predominantly south-facing slopes. Dashed lines in the tree represent omitted branches.

\section{DisCUSSION}

\section{Environmental Characteristics of the Fushan Landscape}

The Fushan Forest is characterized by mountainous terrains and the two creeks that cut across the landscape. Spatial autocorrelation results showed that there are at least three scales at which spatial patterns are apparent in the Fushan landscape. One scale is that of the whole Fushan Forest area $(>3,000 \mathrm{~m})$ and is dominated by the elevational gradient from the high areas in the north to the low areas toward the low valleys in the southeast and southwest. Another is approximately $550 \mathrm{~m}$, and reflects the topography of alternating ridges and valleys predominantly along the east-west direction carved out by the creeks. A third scale is approximately $250 \mathrm{~m}$ and separates the topography in the north-south direction by aspect into north- 

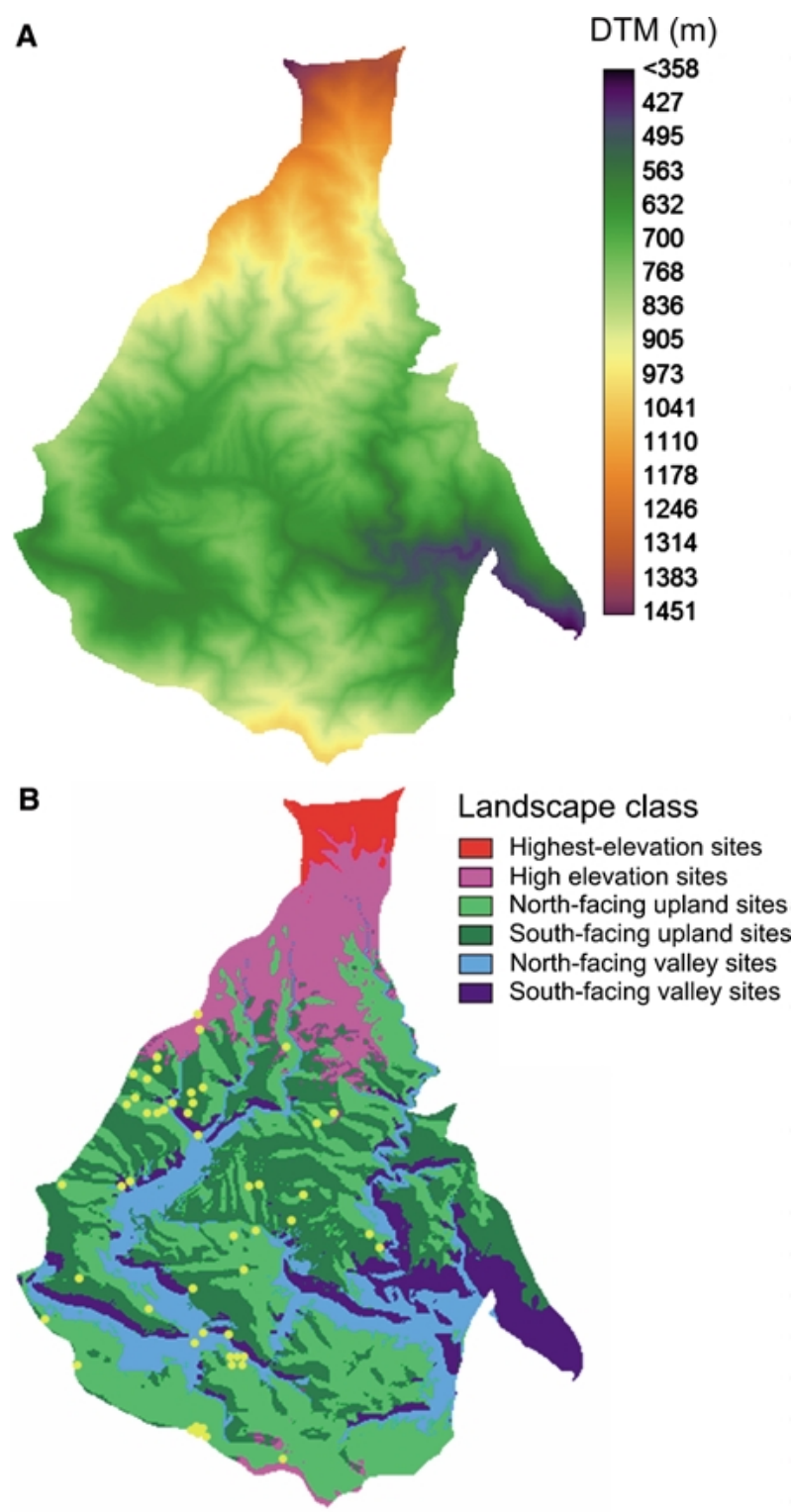

Figure 5. Terrain of the Fushan Forest $(\mathbf{A})$ and its six landscape classes $(\mathbf{B})$. The terrain (DTM) is shown in color shading with red indicating high elevations and blue indicating low elevations. Locations of the vegetation sample plots are indicated with yellow dots.

and south-facing slopes with different variances in total radiation. Other dominant scales may be present in the landscape, but our findings are limited by the resolution of our data.

The landscape classification results also capture the previously mentioned three important gradients in the landscape by classifying the landscape first according to elevational difference (separation of higher areas), then by topographic position (upland and valley areas), then by aspect (northfacing and south-facing slopes).
The PCA results from the whole study area, on the other hand, capture elevation and mean radiation in the first axis and southness in the second axis, but they fail to find topographic position to be important because of its high correlation with elevation (0.647). This finding suggests that although linear methods without separation of scales can pick up major gradients at the scale of the whole study area, they may fail to detect important gradients at finer scales. Therefore, in terms of capturing the important environmental gradients at different scales, linear methods such as PCA are not as useful as spatial analyses such as spatial autocorrelation and landscape classification.

\section{Environmental Characteristics of the Vegetation Plots Compared to Those of the Whole Fushan Forest Area}

Although the vegetation sample plots provided mean values of elevation, direct solar radiation, and total solar radiation that were close to those of the whole study area, with only 53 sites, the vegetation plots had a much more limited representation of data ranges. More important, the plots were biased toward the mid-elevation and flatter portions nearer the center and south of the landscape. For example, $77 \%$ of the vegetation sample plots were in the mid-elevation uplands, less than $6 \%$ were from the high-elevation class, and none were from the highest sites. As a result, they covered only $37 \%$ of the full elevational range and were on average less steep and more open (less sky space blocked) than the whole study area. All of these findings indicate a flaw in the experimental design, such that the steeper and the less open areas in the northern part of landscape (Figure 5) were less represented.

Because the vegetation samples were more representative of the medium- to low-elevation sites of the Fushan Forest, the strong elevational gradient seen in the whole study area (Figure 6A) was not as distinct in the vegetation plots (Figure 7A). The PCA results from the vegetation plots also differed from those of the whole study area in that topographic position replaced elevation as the most dominant gradient in the physical environment (Table 5). In other words, because of the limited scope of the vegetation plots, they captured the second and third gradients in the landscape (topographic position and aspect) but could not detect the first gradient (elevation) as an independently important gradient in the landscape. 

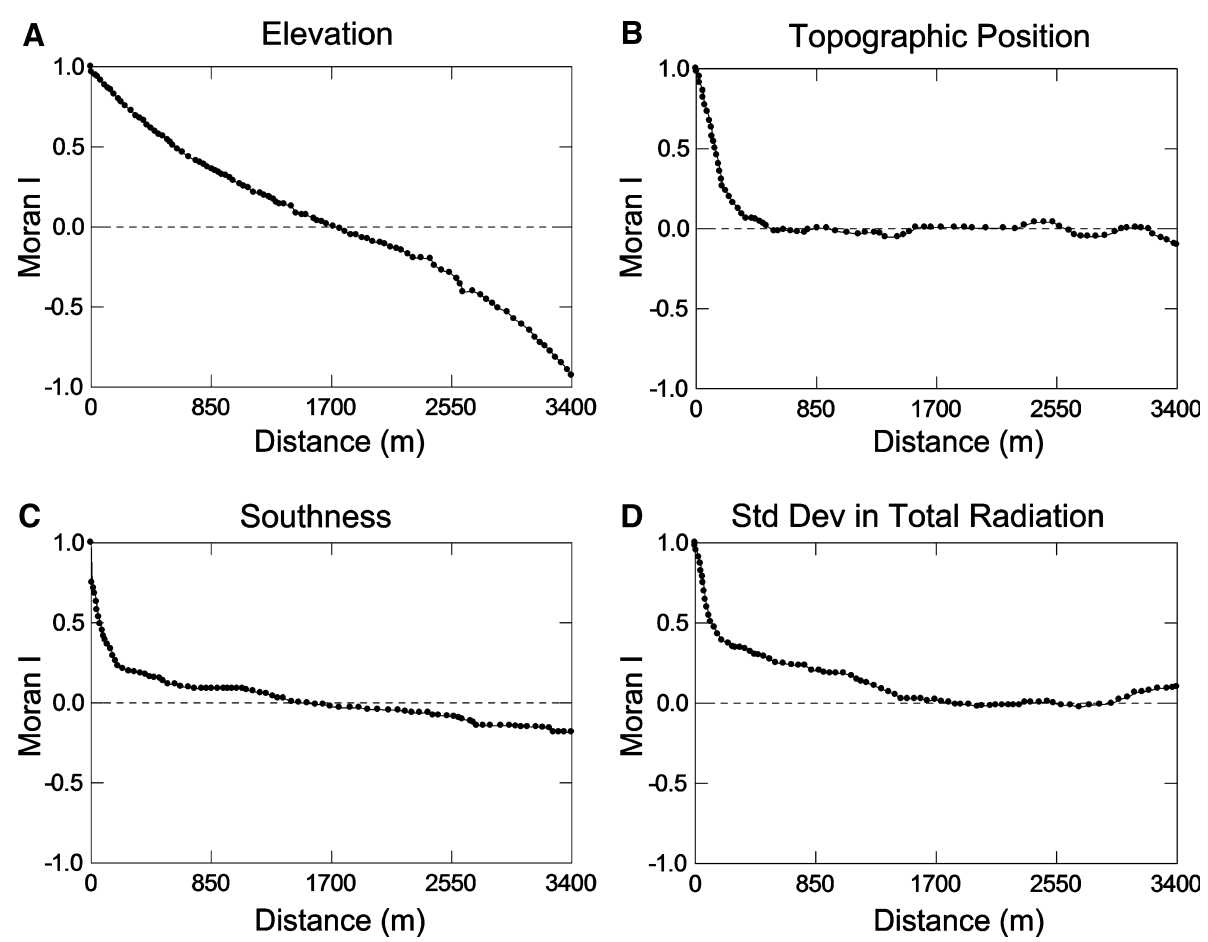

A
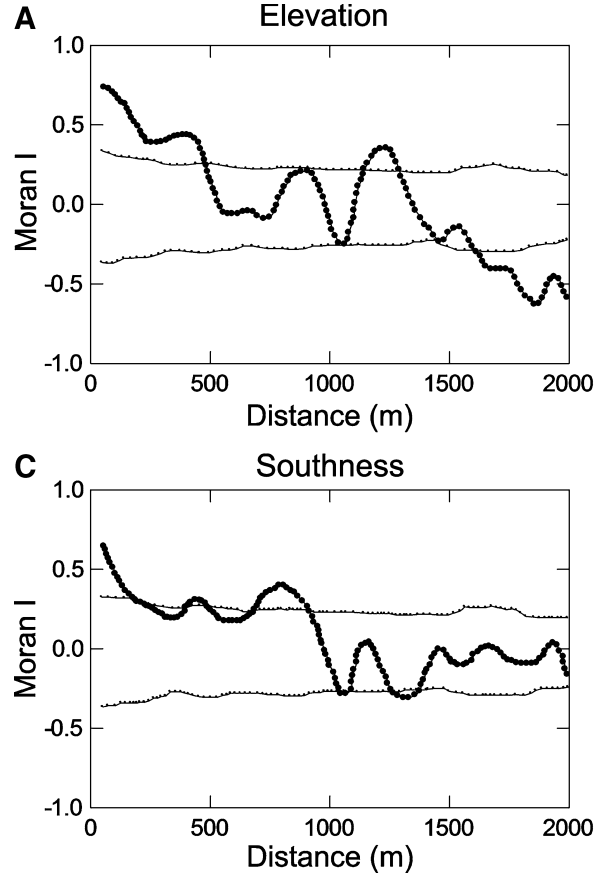
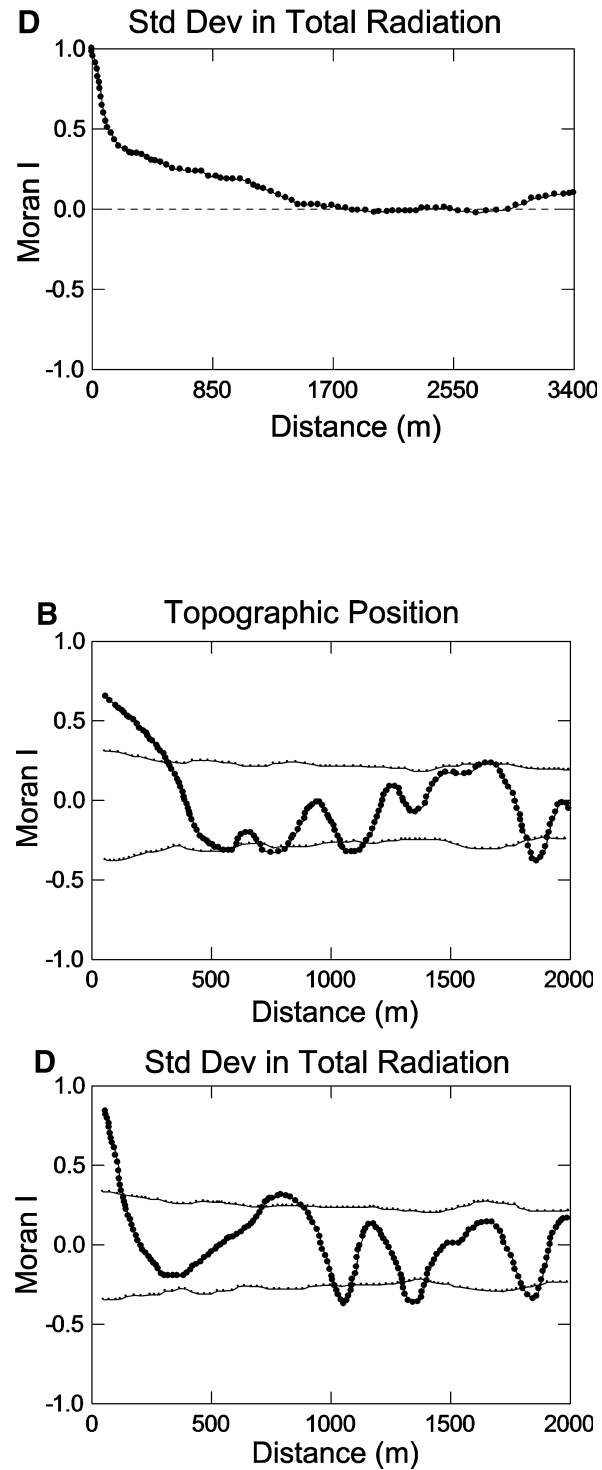

Figure 6. Spatial autocorrelation of selected environmental variables in Fushan Forest (1,098 ha). Elevation (A), topographic position (B), southness $(\mathbf{C})$, and standard deviation in total radiation $(\mathbf{D})$. The solid lines are the calculated Moran's I; the dark lines inseparable near the zero line represent $95 \%$ confidence limits.
Figure 7. Spatial autocorrelation of the environmental variables in the 53 vegetation plots. Elevation (A), topographic position (B), southness $(\mathbf{C})$, and standard deviation in total radiation $(\mathbf{D})$. The solid lines are the calculated Moran's I; the dashed lines represent the permutated $95 \%$ confidence limits.

\section{Implications of the Gradient Analysis} Results

Results from both the gradient analysis and vegetation classification found that topographic position was the most important gradient contributing to the differences in vegetation across the landscape and that variation (SD) in direct radiation second in importance. Because the SD in direct radiation is correlated with southness (correlation coefficient $=$ $-0.530)$, this suggests that the vegetation is responding to aspect. In an independent study in a 
1.4-ha permanent plot in the Fushan Forest, Wang and others (2000) also found topographic position to be the major factor determining vegetation composition in this area, thus confirming our results.

It would thus seem reasonable to suggest that topographic position is the most important environmental factor affecting the vegetation of the Fushan Forest. Considering the results from the spatial analysis of the whole Fushan landscape, it may seem strange that the vegetation of the $\mathrm{Fu}$ shan Forest is responding only to the lesser two of the three major gradients in the landscape, topographic position and aspect, but not to the largerscale gradient, elevation, which is usually an important determining factor of vegetation. Through analysis of environmental variables in the vegetation plots, however, we were able to recognize that the conclusions from the vegetation analyses are highly subjective to the biases of the vegetation plots, which were not sufficiently extensive in coverage, and were therefore inadequate to capture the elevational gradient across the landscape. A review of the Methods section in the Wang and others (2000) paper confirms that their plot was set in the 690-820-m elevation zone and is therefore equally limited in terms of spatial coverage.

As a consequence, inferences derived from the vegetation analyses in this study are applicable to within $550 \mathrm{~m}$ of the samples, that is, the mid- to lower-elevation zones toward the southern twothirds of the Fushan Forest. To make inferences about vegetation dynamics in the higher zones or vegetation changes in response to temperature changes, however, one would need more information on the vegetation in the higher-elevation zones (the Highest and High zones in Figure 5B) and their environmental responses. By identifying the regions in which vegetation data are limited, guidelines for future sampling designs can be established. Anecdotal observations by C.-M. Kuo (in Chang 1998) suggest that the vegetation in the Fushan Forest is greatly influenced by elevation, especially in that the vegetation in the higher parts toward the north is very different from that in the remainder of the forest. We therefore believe that additional information from the northern and higher parts of the forest will show that all three major gradients-elevation, topographic position, and aspect-are important factors influencing vegetation composition in the Fushan Forest.

Thanks to the extensive development of geographical information databases worldwide, spa- tially explicit information concerning environment variables such as those used in this study are increasingly available. Also, in addition to spatial autocorrelation analysis and landscape classification, many other spatial analysis tools are available, such as spectral analysis, fractals, multiscale ordination, Fourier transformation, Quadtrees, wavelets, and scale-space (Turner and others 1991; Marceau 1999; Fortin 1999; Hay and others 2002).

We suggest three ways in which spatial analyses may be used to develop guidelines for appropriate ranges and scales for the extrapolation of smallscale field study data and for the identification of new information needed to extend the scope of extrapolation. First, spatial analyses can be used to add supplementary information to earlier field studies, so that the scale thresholds for the extrapolation of results may be acquired. Second, in cases where the resources are available, additional survey plots may be added according to the results of spatial analysis, so that the extrapolation of the combined old and new data can be extended to a wider scope with more confidence. Finally, spatial analysis may be used to aid in the planning and revision of field survey designs prior to their implementation, making it possible to obtain sufficient and properly located samples that will capture the important gradients of the landscape(s) upon which the survey results will be extrapolated. With such efforts, valuable and hard-earned field data can then be used to make more contributions to our understanding of scale in ecology.

\section{ACKNOWLEDGEMENTS}

This study was funded in part by the National Science Council of the Republic of China. We thank Dr. Kuo-Chuan Lin for the soil maps, Dr. Dean Urban for the algorithms of the spatial autocorrelation analyses, and two anonymous referees for their constructive comments on an earlier manuscript.

\section{REFERENCES}

Barnes BV, Pregitzer KS, Spies TA, Spooner VH. 1982. Ecological forest site classification. J For 80:493-8.

Betts RA, Cox PM, Lee SE, Woodward FI. 1997. Contrasting physiological and structural vegetation feedbacks in climate change simulations. Nature 387:796-9.

Böhning-Gaese K, Taper ML, Brown JH. 1994. Avian community dynamics are discordant in space and time. Oikos 70: $121-6$.

Bonan GB. 1989. A computer model of the solar radiation, soil moisture, and thermal regimes in boreal forests. Ecol Model 45:275-306. 
Bunce RGH, Barr CJ, Clarke RT, Howard DC, Lane AMJ. 1996. ITE Merlewood land classification of Great Britain. J Biogeogr 23:625-34.

Chang C-R, Lee P-F, Bai M-L, Lin T-T. 2004. Predicting the geographical distribution of plant communities in complex terrain-a case study in Fushan Experimental Forest, northeastern Taiwan. Ecography 27:577-88.

Chang F-H, Wang S, Wang Y, Lin Y-S, Lue K-Y, Severinghaus LL, Hsu K-S. 1986. The survey on the natural resources of Ha-pen area. Ecological Research Report No. 13. Taipei: Council of Agriculture, Republic of China. 102 p.

Chang Y-H. 1998. The study of the relationship between the distribution of pteridophytes and environmental factors at Fushan area in North Taiwan, and estimating the utility of ferns as the microenvironmental indicators [thesis]. Taipei: National Taiwan University. (in Chinese).

Cherrill AJ, Lane A. 1995. The survey and prediction of land cover using an environmental land classification. Appl Geogr 15:69-85.

Cherrill AJ, McClean C, Watson P, Tucker K, Rushton SP, Sanderson R. 1995. Predicting the distributions of plant species at the regional scale: a hierarchical matrix model. Landscape Ecol 10:197-207.

Ehleringer JR, Field CB. 1993. Scaling physiological processes: leaf to globe. San Diego: Academic, 388.

Entin JK, Robock A, Vinnikov KY, Hollinger SE, Liu SX, Namkhai A. 2000. Temporal and spatial scales of observed soil moisture variations in the extratropics. J Geophys Res 105(D9):11865-77.

[ESRI] Environmental Systems Research Institute. 1997. ARC/INFO 7.2. Redlands (CA): Environmental Systems Research Institute.

Farquhar GD, von Caemmerer S. 1982. Modelling of photosynthetic response to environmental conditions. In: Lange OL, Nobel PS, Osmond CB, Ziegler H, Eds. Physiological plant ecology II: water relations and carbon assimilation; vol $12 \mathrm{~b}$. Berlin Heidelberg New York: Springer. p 549-87.

Farquhar GD, von Caemmerer S, Berry JA. 1980. A biochemical model of photosynthetic $\mathrm{CO}_{2}$ assimilation in leaves of $\mathrm{C} 3$ species. Planta 149:78-90.

Fortin MJ. 1999. Spatial statistics in landscape ecology. In: Klopatek JM, Gardner RH, Eds. Landscape ecological analysis: issues and applications. New York, New York: Springer. p 253-79.

Greig-Smith P. 1979. Pattern in vegetation. J Ecol 67:755-79.

Hall O, Hay GJ, Bouchard A, Marceau DJ. 2004. Detecting dominant landscape objects through multiple scales: an integration of object-specific methods and watershed segmentation. Landscape Ecol 19:59-76.

Harmon ME, Marks B. 1995. Programs to estimate the solar radiation for ecosystem models. H. J. Andrews LTER. Available online at: http://www.fsl.orst.edu/lter/data/software/ solarrad/solarrad.txt.

Hay GJ, Marceau DJ, Dube P, Bouchard A. 2001. A multiscale framework for landscape analysis: object-specific analysis and upscaling. Landscape Ecol 16:471-90.

Hay GJ, Dube P, Bouchard A, Marceau DJ. 2002. A scale-space primer for exploring and quantifying complex landscapes. Ecol Model 153:27-49.

Hill MO, Gauch HG. 1980. Detrended correspondence analysis, an improved ordination technique. Vegetation 42:47-58.

Holdridge LR. 1947. Determination of world plant formations from simple climatic data. Science 105:367-8.
Hsia Y-J, Wang W-S. 1985. Calculation of potential solar irradiance on slopes. Research Note No. 001. Taipei: Taiwan Forestry Research Institute. (in Chinese with English summary).

Insightful. 2001. S-Plus 6 for Windows guide to statistics; vol 2. Seattle: Insightful Corporation.

Jarvis PG. 1995. Scaling processes and problems. Plant Cell Environ 18:1079-89.

Jarvis PG, McNaughton KG. 1986. Stomatal control of transpiration: scaling up from leaf to region. Adv Ecol Res 15:1-49.

Kareiva P, Andersen M. 1986. Spatial aspects of species interactions: the wedding of models and experiments. In: Hastings A, Ed. Community ecology. Berlin Heidelberg: New York: Springer. p 35-50.

King AW. 1991. Translating models across scales in the landscape. In: Turner MG, Gardner RH, . Quantitative methods in landscape ecology. Berlin Heidelberg: New York: Springer. p 479-517.

Kuo C-M. 1994. Long-term ecological research in Fushan forest-understory vegetation. In: Peng C-I, Chou C-H, Eds. Biodiversity and terrestrial ecosystems. Academia Sinica Monograph Series No. 14. Taipei: Institute of Botany. p 383-99.

Legendre P. 1993. Spatial autocorrelation: trouble or new paradigm? Ecology 74:1659-73.

Levin SA. 1992. The problem of pattern and scale in ecology. Ecology 73:1943-83.

Lin K-C, Horng F-W, Cheng W-E, Chiang H-C, Chang U-C. 1996. Soil survey and classification of the Fushan Experimental Forest. Taiwan J For Sci 11:159-74(in Chinese with English summary).

Lin T-T. 1997. Vegetation of Fushan Forest. In: Chou C-H, Ed. Introduction of Taiwan Long-Term Ecological Research, a special issue of Taiwan LTER Newsletter, No. 1. Taipei. Republic of China: National Science Council. p 15-6.

Lin T-T, Ma F-G, Chang N-H. 1995. The study of vegetation and natural regeneration in Fushan Experimental Forest. In: Horng F-W, Ed. Proceedings of the symposium at the centenary celebration of Taiwan Forestry Research Institute, Taipei, Taiwan, 4-6 January 1995. Taipei: Taiwan Forestry Research Institute. p 71-81 (in Chinese).

Mabery CM, Hamburg SP, Lin T-C, Horng F-W, King H-B, Hsia Y-J. 1998. Typhoon disturbance and stand-level damage patterns at a subtropical forest in Taiwan. Biotropica 30:238-50.

Marceau DJ. 1999. The scale issue in social and natural sciences. Can J Remote Sens 25:347-56.

Marceau DJ, Hay GJ. 1999. Remote sensing contributions to the scale issue. Can J Remote Sens 25:357-66.

McCune B, Mefford MJ. 1999. PC-ORD - multivariate analysis of ecological data; Ver 4. Gleneden Beach (CA): MJM Software Design.

Meentemeyer V. 1989. Geographical perspectives of space, time, and scale. Landscape Ecol 3:163-73.

Meisel JE, Turner MG. 1998. Scale detection in real and artificial landscapes using semivariance analysis. Landscape Ecol 13:347-62.

Merrill T, Wright RG, Scott JM. 1995. Using ecological criteria to evaluate wilderness planning options in Idaho. Environ Manage 19:815-25.

Mladenoff DJ, Sickely TA, Haight RG, Wydeven AP. 1995. A regional landscape analysis and prediction of favorable gray wolf habitat in the northern Great Lakes region. Conserv Biol 9:279-94. 
Mohanty BP, Famiglietti JS, Skaggs TH. 2000. Evolution of soil moisture spatial structure in a mixed vegetation pixel during the Southern Great Plains 1997 (SGP97) hydrology experiment. Water Resources Res 36:3675-86.

Nikolov NT, Zeller KF. 1992. A solar radiation algorithm for ecosystem dynamic models. Ecol Model 61:149-68.

O'Neill RV, DeAngelis DL, Waide JB, Allen TFH. 1986. A hierarchical concept of ecosystems. Princeton:(NJ) Princeton University Press.

Prentice IC, Cramer W, Harrison SP, Leemans R, Monserud RA, Solomon AM. 1992. A global biome model based on plant physiology and dominance, soil properties and climate. J Biogeogr 19:117-34.

Rastetter EB, King AW, Cosby BJ, Hornberger GM, O'Neill RV, Hobbi JE. 1992. Aggregating fine-scale ecological knowledge to model coarser-scale attributes of ecosystems. Ecol Appl 2:55-70.

Reynolds JF, Bugmann H, Pitelka LF. 2001. How much physiology is needed in forest gap models for simulating long-term vegetation response to global change? Challenges, limitations, and potentials. Clim Change 51:541-57.

Ripley BD. 1981. Spatial statistics. New York:Wiley.

Rossi RE, Mulla DJ, Journel AG, Franz EH. 1992. Geostatistical tools for modeling and interpreting ecological spatial dependence. Ecol Monogr 62:277-314.

SAS Institute. 1994. SAS. Cary (NC): SAS Institute.

Schimel D, Melillo J, Tian H, McGuire AD, Kicklighter D, Kittel $\mathrm{T}$, Rosenbloom N, and others. 2000. Contribution of increasing $\mathrm{CO}_{2}$ and climate to carbon storage by ecosystems of the United States. Science 287:2004-6.

Schneider DC, Piatt JF. 1986. Scale-dependent correlation of seabirds with schooling fish in a coastal ecosystem. Mar Ecol Prog Ser 32:237-46.

Sokal RR, Oden NL. 1978. Spatial autocorrelation in biology. 1. Methodology. Biol J Linn Soc 10:199-228.

Taper ML, Böhning-Gaese K, Brown JH. 1995. Individualistic species responses to environmental variation. Oecologia 101:478-86.

Tilman D. 1989. Ecological experimentation: strengths and conceptual problems. In: Likens GE, Ed. Long-term studies in ecology approaches and alternatives. Berlin Heidelberg New York: Springer. p 136-57.

Turner MG, Dale VH, Gardner RH. 1989. Predicting across scales: theory development and testing. Landscape Ecol 3:245-52.

Turner SJ, O'Neill RV, Conley W, Conley MR, Humphries HC. 1991. Pattern and scale: Statistics for landscape ecology. In: Turner MG, Gardner RH, Eds. Quantitative methods in landscape ecology. Berlin Heidelberg New York: Springer. $\mathrm{p}$ 17-50.

Urban DL, Miller C, Halpin PN, Stephenson NL. 2000. Forest gradient response in Sierran landscapes: the physical template. Landscape Ecol 15:603-20.

Wang H-H, Pan F-J, Liu C-K, Yu Y-H, Hung S-F. 2000. Vegetation classification and ordination of a permanent plot in the Fushan Experimental Forest, northern Taiwan. Taiwan J For Sci 15:411-28 (in Chinese with English summary).

Western AW, Grayson RB, Bloschl G. 2002. Scaling of soil moisture: a hydrologic perspective. Annu Rev Earth Pl Sc 30:149-80.

Western AW, Zhou S-L, Grayson RB, McMahon TA, Blöschl G, Wilson DJ. 2004. Spatial correlation of soil moisture in small catchments and its relationship to dominant spatial hydrological processes. J Hydrol 286:113-34.

Wiens JA. 1989. Spatial scaling in ecology. Funct Ecol 3:385-97.

Woodward FI. 1987. Climate and plant distribution. Cambridge (UK): Cambridge University Press.

Wright RG, MacCracken JG, Hall J. 1994. An ecological evaluation of proposed new conservation areas in Idaho: evaluating proposed Idaho national parks. Conserv Biol 8:207-16.

Wright RG, Murray MP, Merrill T. 1998. Ecoregions as a level of ecological analysis. Biol Conserv 86:207-13.

Wu J. 1999. Hierarchy and scaling: extrapolating information along a scaling ladder. Can J Remote Sens 25:367-80.

Wu J, Loucks OL. 1995. From balance of nature to hierarchical patch dynamics: a paradigm shift in ecology. Q Rev Biol 70:439-66.

Wu J, Levin SA. 1997. A patch-based spatial modeling approach: conceptual framework and simulation scheme. Ecol Model 101:325-46. 